\title{
ATRIBUTOS BIOCLIMÁTICOS URBANOS UMA ANÁLISE SOBRE O PONTO DE VISTA QUALITATIVO
}

\author{
Fernanda Miguel Franco ${ }^{(1)}$; Marta Cristina de Albuquerque Nogueira ${ }^{(2)}$; Carlo Ralph De Musis ${ }^{(3)}$; \\ Luciane Cleonice Durante ${ }^{(4)}$; José de Souza Nogueira ${ }^{(5)}$
}

(1) Doutoranda do Programa de Pós-Graduação em Física Ambiental, e-mail: fermifran@hotmail.com

(2) Profa. Dra . do Departamento de Arquitetura e Urbanismo e Programa de Pós-Graduação em Física Ambiental - UFMT, e-mail: mcjanp@gmail.com

(3) Prof. Dr. do Programa de Pós-Graduação em Física Ambiental, e-mail: carlo.demusis@gmail.com

(4) Profa. Dra. do Departamento de Arquitetura e Urbanismo - UFMT, e-mail: luciane.durante@hotmail.com

(5) Prof. Dr. do Departamento de Física e Coordenador do Programa de Pós-Graduação em Física Ambiental, e-mail: nogueira@ufmt.com.br

http://dx.doi.org/10.5902/223613087175

\section{RESUMO}

As discussões mais recentes apontam a sustentabilidade como medida obrigatória para o desenvolvimento técnico e cientifico. As cidades seguem um padrão de crescimento e organização que envolve interesses econômicos, políticos e sociais, sendo assim a malha urbana possui padrões diversos de formação. A capital do Mato Grosso Cuiabá é uma cidade do início do século XVIII, sua formação inicial constituía-se da região central cruzada pelo córrego da Prainha e a região do Porto as margens do rio Cuiabá. O bairro Porto possui uso e ocupação do solo misto, residencial, comercial, prestadoras de serviços e institucional. As características de ocupação podem definir que o bairro possui pouca densidade construída, notando-se uma grande quantidade de área verde preservada. $O$ objetivo do presente trabalho é fazer uma análise através da ficha bioclimática em vários pontos localizados em regiões diferentes do bairro Porto, a metodologia adotada foi de Romero (2001), a mesma trata das constantes bioclimáticas juntamente com os elementos formais do edifício e do espaço urbano. Na analise geral temos condições de verificar qual o padrão geométrico urbano, assim como sugerir qual a melhor opção para o direcionamento do desenvolvimento de espaços mais sustentáveis.

Palavras-chave: Sustentabilidade Urbana, Conforto Ambiental, Bioclimatologia

\section{ABSTRACT}

Recent discussions indicate sustainability as a compulsory measure for the technical and scientific development. Cities follow a pattern of organization that involves growth and economic interests, political and social, so the urban area has a number of training patterns. The capital of Mato Grosso, Cuiabá is a city in the early eighteenth century, their initial training was from the central region crossed by the stream of Prainha and Porto region the banks of the River Cuiabá. The port district has land use and soil mix consisting of residences, businesses, service providers and institutions. The characteristics of occupation can define the neighborhood has sparsely built, noting a large amount of green area preserved. The objective of this study is to analyze through bioclimatic form at various points located in different regions of the Port district, the methodology was adopted, Romero (2001), the same set of bioclimatic comes along with the formal elements of the building and space urban, with an emphasis on the space for public use. In the overall analysis we are able to verify the geometric pattern, urban as well as suggesting what the best option for directing the development of a more sustainable city.

Keywords: Urban Sustainability, Environmental Comfort, Bioclimatology 


\section{INTRODUÇÃO}

A arquitetura produzida vem sendo foco de um olhar unilateral, arquitetura que tem como molde os padrões internacionais de construção deixando assim muito a desejar no que diz respeito a adequação aos anseios locais, discussões apontam a arquitetura bioclimática como o caminho para se obter uma estrutura mais coerente e adequada.

As cidades abrigam a maior parte da população mundial e tem seu desenvolvimento comprometido por políticas publicas ineficientes e em muitos casos até inexistente. Ocupações irregulares em locais de risco, que em momento oportuno são regularizados e recebem infraestrutura de maneira ineficiente. $O$ traçado urbano deve estar comprometido com o bem estar e a qualidade de vida da população urbana, todas as diretrizes para o seu desenvolvimento necessitam de um respaldo cientifico e político contando com uma gama de profissionais de diversas áreas de conhecimento.

A capital do Mato Grosso Cuiabá é uma cidade do início do século XVIII, sua formação inicial constituía-se da região central cruzada pelo córrego da Prainha e a região do Porto as margens do rio Cuiabá. O Bairro Porto fica localizado na região Oeste da cidade. O uso e ocupação do solo local pode ser considerado misto, composto por residências, comércios, prestadoras de serviços e instituição. As características de ocupação pode definir que o bairro possui pouca densidade construída, notando-se uma grande quantidade de área verde preservada, além de inúmeras casas com quintais, conservando o que foi originalmente.

$\mathrm{O}$ bairro Porto vem despertando o interesse do setor imobiliário, onde, observa-se o lançamento de vários empreendimentos, dentre eles, residenciais multifamiliares em locais onde eram áreas de vegetação nativa ainda preservada, que com sua retirada, possivelmente poderá ter influência no microclima local.

O objetivo do presente trabalho, é fazer uma análise qualitativa, através da ficha bioclimática, em 24 pontos localizados em regiões diferentes do bairro Porto. A metodologia adotada foi de Romero (2001), a mesma elenca as constantes bioclimáticas juntamente com os elementos formais do edifício e do espaço urbano, com um destaque para o espaço de uso público.

Essa proposta de estudo visa analisar a concepção bioclimática em escala urbana assim como a arquitetura bioclimática consegue com o edifício transformando em mediador entre o clima externo e o ambiente no interior do espaço público. $O$ entorno incluiu os acessos espaciais que o espaço público apresenta aos elementos ambientais do sol e vento, além das características espaciais da continuidade da massa construída e a condução do ar entre edificações. A base incluiu a caracterização da pavimentação, vegetação, presença de água. A superfície fronteira compreendeu a tipologia arquitetônica, o nível ocupação do terreno e a altura da edificação.

$\mathrm{Na}$ analise geral temos condições de verificar qual o padrão geométrico urbano, assim como sugerir qual a melhor opção para o direcionamento do desenvolvimento de uma cidade mais sustentável.

\section{ÁREA DE ESTUDO}

O bairro Porto está localizado na região Oeste da cidade de Cuiabá-MT, possui uma área de 248,22 ha e uma população de 9.335 pessoas. Apesar de possuir um histórico de crescimento 
que vai de XVIII até 2000 o bairro ainda preserva muito de suas caracteristicas originais (Figura 1).
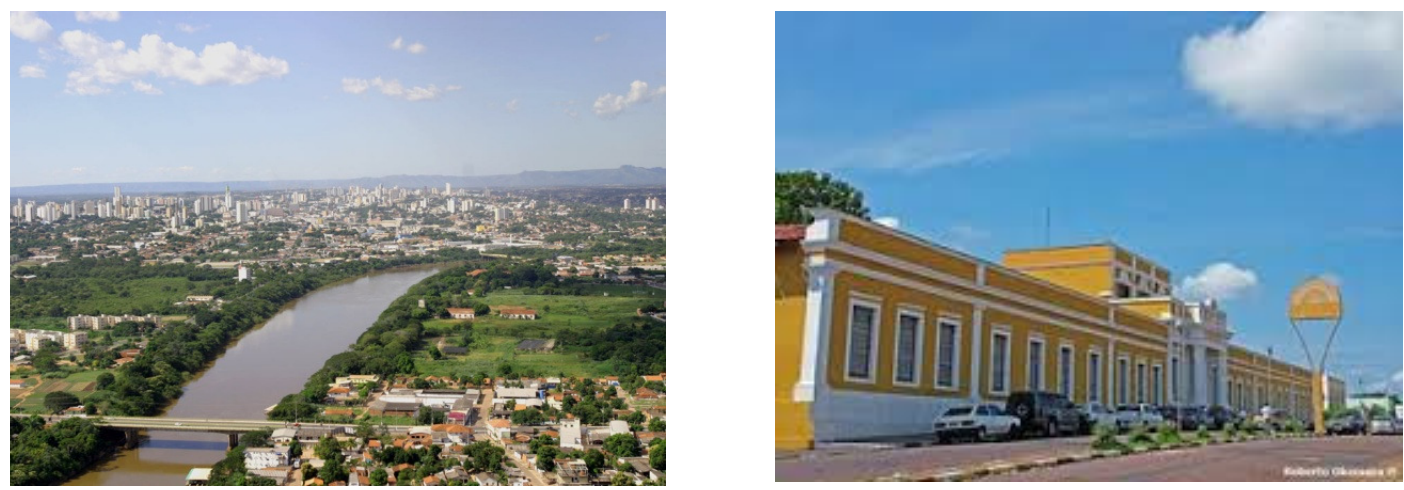

Figura 1 - Rio Cuiabá e SESC Arsenal Porto

Fonte: Do próprio autor

Segundo o plano diretor apresentado pela prefeitura existem algumas ZES (Zonas Urbanas Especiais) no bairro, elas podem ser classificadas em: Zona de Interesse Ambiental 1, Zona de Interesse Social 3, Zona de Área Central e Zona de Interesse Histórico.

O local constitui-se um dos pontos mais antigos de Cuiabá. Após a descoberta das Lavras do Sutil (1722), ocorreu uma expressiva migração dos primeiros povoadores, fixados na região do Coxipó-Mirin, para as margens do Córrego da Prainha. O Porto de Cuiabá passou a ser o destino e a partida dos bandeirantes paulistas, monções embarcadas no Rio Tietê (SP) e que chegavam ao Rio Cuiabá ponto final da viagem, (SIQUEIRA et al, 2007).

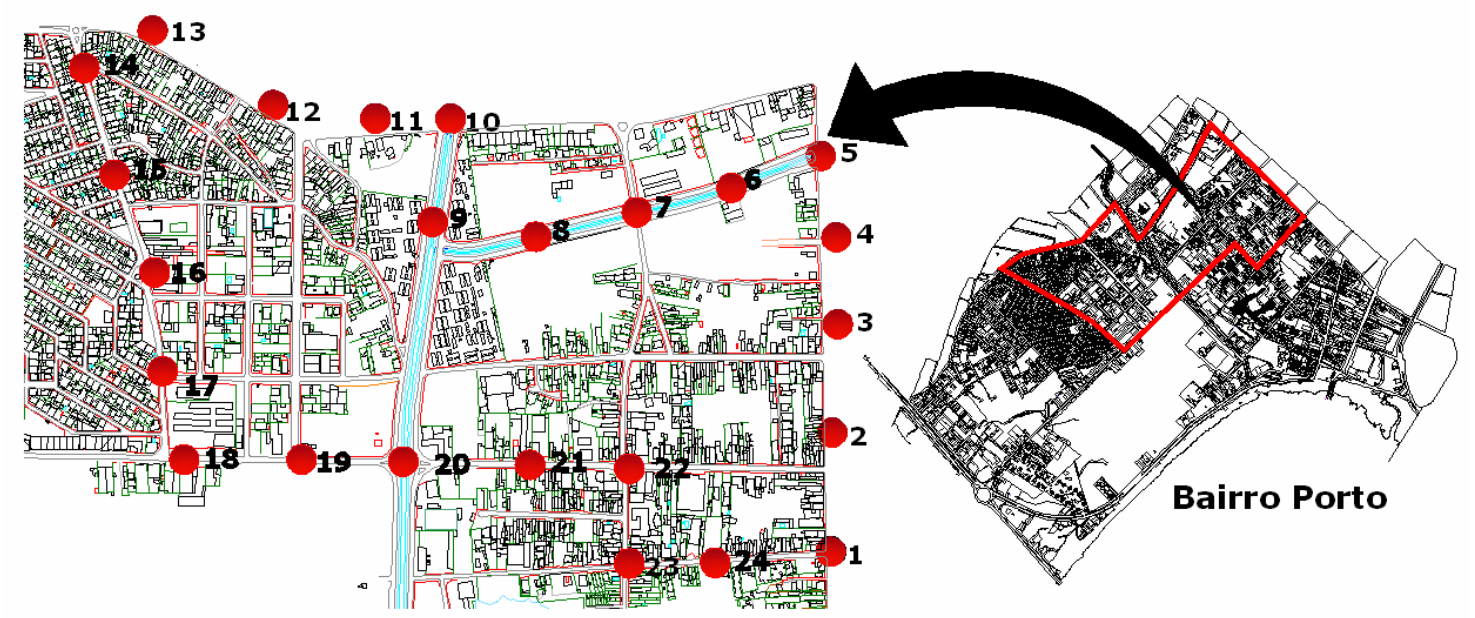

Figura 2 - Localização dos pontos de avaliação bioclimatica e mensuração da tempeatura do ar. Fonte: IPDU Cuiabá, 2009

\section{METODOLOGIA}

Foi realizado um levantamento que analisava as características bioclimáticas locais, através da elaboração de uma ficha a qual deu subsidio para a elaboração da comparação entre os 
pontos estudados. Também foi feito um levantamento da temepratura do ar, por meio da elaboração do transecto móvel.

A ficha bioclimatica utilizando a metodologia de Romero (2001) trata das constantes bioclimáticas com a junção dos elementos formais do edifício e do espaço urbano. É uma proposta de concepção bioclimática que, em escala urbana, visa obter o que a arquitetura bioclimática consegue com o edifício: transformá-lo em mediador entre o clima externo e o ambiente no interior do espaço público. O entorno incluiu os acessos espaciais que o espaço público apresenta aos elementos ambientais do sol e vento, além das características espaciais da continuidade da massa construída e a condução do ar entre edificações. A base incluiu a caracterização da pavimentação, vegetação, presença de água. A superfície fronteira compreendeu a tipologia arquitetônica, o nível ocupação do terreno e a altura da edificação.

Para a análise dessas condicionantes elaborou-se um quadro na qual atribuiu-se um valor para cada característica, baseado no mapa comportamental das respectivas a'reas pesquisadas, considerando-se desde as mais desfavoraveis com exposição continua ao sol até as mais favoráveis com sombreamento, segundo o Quadro1 a seguir.

Juntamente com o levantamento dos dados qualitativos tambám fez-se o levantamento da variável ambiental, temperatura do ar, realizada por meio de coletas móveis, que foram realizadas com o método do transecto móvel, com um termohigroanemômetro protegido por um abrigo, confeccionado com PVC e perfurado para garantir a circulação de ar, acoplado ao veículo (carro) a uma altura de $1,50 \mathrm{~m}$ do solo, percorrendo os 24 pontos determinados.

Quadro 1 - Classificação bioclimática (Fonte: Do próprio autor)

\begin{tabular}{|c|c|c|c|}
\hline \multicolumn{4}{|l|}{ QUADRO DE CLASSIFICAÇÃO } \\
\hline \multicolumn{4}{|l|}{ ENTORNO LOCALIZAÇÃO } \\
\hline \multirow{2}{*}{ Sol } & Exposto & Parcial Exposto & Sombra \\
\hline & 1 & 2 & 3 \\
\hline \multirow{2}{*}{ Densidade } & Alta & Média & Baixa \\
\hline & 1 & 2 & 3 \\
\hline \multirow{2}{*}{ Uso do Solo } & Comercial & Misto & Residencial \\
\hline & 1 & 2 & 3 \\
\hline \multirow{2}{*}{ Transito de veículos } & Alta & Médio & Baixo \\
\hline & 1 & 2 & 3 \\
\hline \multicolumn{4}{|l|}{ BASE } \\
\hline \multirow{2}{*}{ Pavimentação } & Imper.Asfalto & Imperm. Outros & Solo Nú \\
\hline & 1 & 2 & 3 \\
\hline \multirow{2}{*}{ Vegetação } & Pouca rasteira & Arvores Médias & Arvores Grandes \\
\hline & 1 & 2 & 3 \\
\hline \multirow{2}{*}{ Água } & Distante & Próximo & \\
\hline & 1 & 2 & \\
\hline \multicolumn{4}{|l|}{ SUPERFICIE FRONTEIRA } \\
\hline \multirow{2}{*}{ Tipologia Arquitetônica } & Comercial & Residencial & Terreno Vazio \\
\hline & 1 & 2 & 3 \\
\hline \multirow{2}{*}{ Numero de lados ocupados } & Sem afastamento & Afast. Frontal & Afast. Front. Lat. \\
\hline & 1 & 2 & 3 \\
\hline \multirow{2}{*}{ Altura } & Mais de 2 pav. & Térreo & Sem Construção \\
\hline & 1 & 2 & 3 \\
\hline
\end{tabular}




\section{ANÁLISES E DISCUSSÕES}

Tendo em vista o crescimento da malha urbana em Cuiabá, o bairro Porto ainda apresenta algumas características que trazem beneficio ao desempenho microclimático local, como exemplo disso nota-se a vegetação de mata ciliar ao longo do rio Cuiabá, vias arborizadas, reserva de mata nativa, esses são alguns atributos que podem somar de maneira positiva para o conforto ambiental.

Em uma análise qualitativa das condicionantes positivas no quesito ocupação urbana, podemos citas três, como sendo de extrema importância, principalmente em relação ao clima, são elas: Presença de vegetação, proximidade com água e tipos de pavimentação. $O$ grande vilão do aquecimento urbano é sem duvida os tipos de pavimentação e os materiais empregados nas construções, pois esses elementos podem alterar de maneira significativa o seu entorno.

A cidade modifica o clima através das alterações em sua superfície, produzindo aumento de energia térmica, modificações no fluxo de vento, diminuição da umidade relativa, e diminuição da infiltração da água das chuvas, em função do aumento da superfície impermeável formada pela pavimentação e área construída. Isso ocorre porque a substituição dos materiais naturais pelos materiais urbanos provoca mudanças nos processos de absorção, transmissão e reflexão, e nas características da atmosfera local (DUARTE, 2000).

Em estudo recente realizado em Atenas na Grécia, Santamouris et al. (2012) realiza a aplicação de $4500 \mathrm{~m}^{2}$ de pavimentos reflexivos em um parque urbano com o objetivo de melhorar as condições de conforto e reduzir a intensidade da ilha de calor. Para avaliar o impacto térmico de arrefecimento do material foram feitas análises das condições climáticas antes e depois da aplicação dos revestimentos, ao final do experimento estimou-se que a utilização de pavimentos frescos contribui para a redução da temperatura de pico durante um dia típico de verão em até $1,9^{\circ} \mathrm{C}$. Ao mesmo tempo, a temperatura da superfície reduziu $12^{\circ} \mathrm{C}$, permitindo que as condições de conforto fossem consideravelmente melhoradas.

\section{Dados Qualitativos}

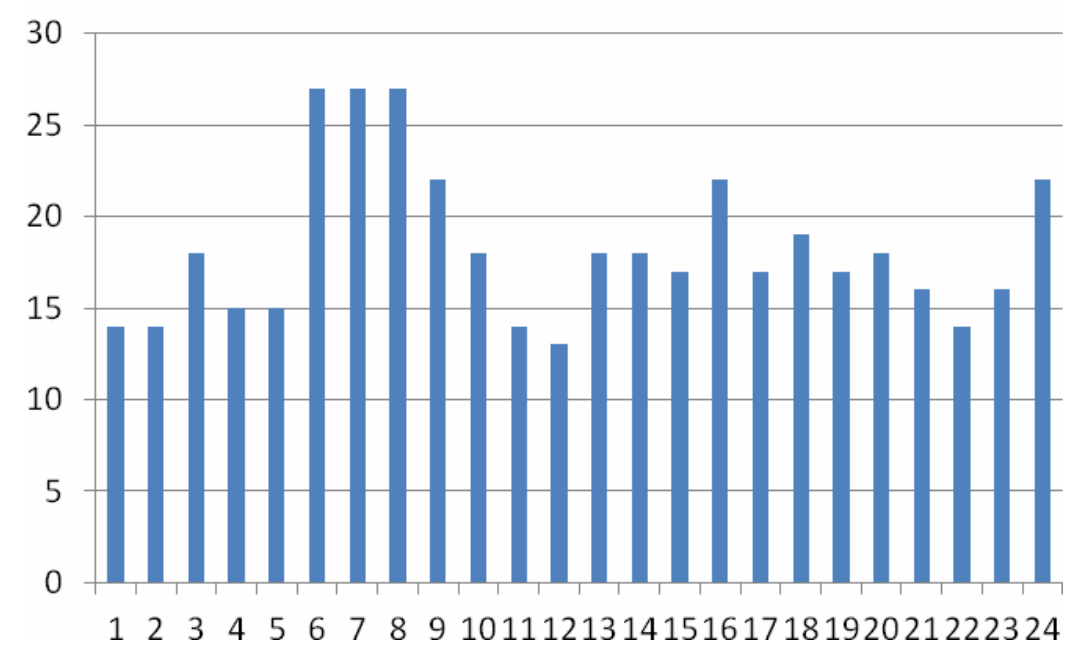

Figura 3 - Desempenho bioclimática 
Em cidades de clima quente deve-se utilizar revestimentos mais reflexivos, ou seja, que quando submetidos a incidência solar, absorvam uma pequena parcela da radiação, provocando assim menores alterações na sua temperatura inicial. Esses materiais permitem que uma menor parcela da radiação seja emitida em forma de calor tanto para o ambiente externo quanto para o interno.

$\mathrm{Na}$ analise dos dados observa-se que os pontos de menor desempenho bioclimático são 1,2 , 4, 5, 11 e 12 (Figura 3), não coincidentemente também os pontos que apresentam maior taxa de urbanização e de impermeabilização do solo. Na figura 5 nota-se também que em relação a tempertatura do ar foram os pontos que obtiveram as maiores médias.

Os melhores índices bioclimáticos foram encontrados nos pontos 6, 7, 8, 16 e 24, locais onde encontrava-se vegetação e a presença de água. Givoni (1994) coloca o sombreamento como pré-requisito para os espaços externos antes de qualquer outra medida, porque a proteção à radiação solar tem um grande efeito psicológico na redução do stress térmico. Em estudos realizados por Limor Shanshua-Bar et. al. (2010) em Atenas o efeito de atenuação que a vegetação pode proporcionar nas temperaturas do ar observadas nas ruas pode atingir $5^{\circ} \mathrm{C}$ ao meio-dia, tendo um arrefecimento médio diário de $3^{\circ} \mathrm{C}$. Assim o efeito da presença de vegetação pode ser um fator muito importante para a melhoria do microclima do bairro em questão.

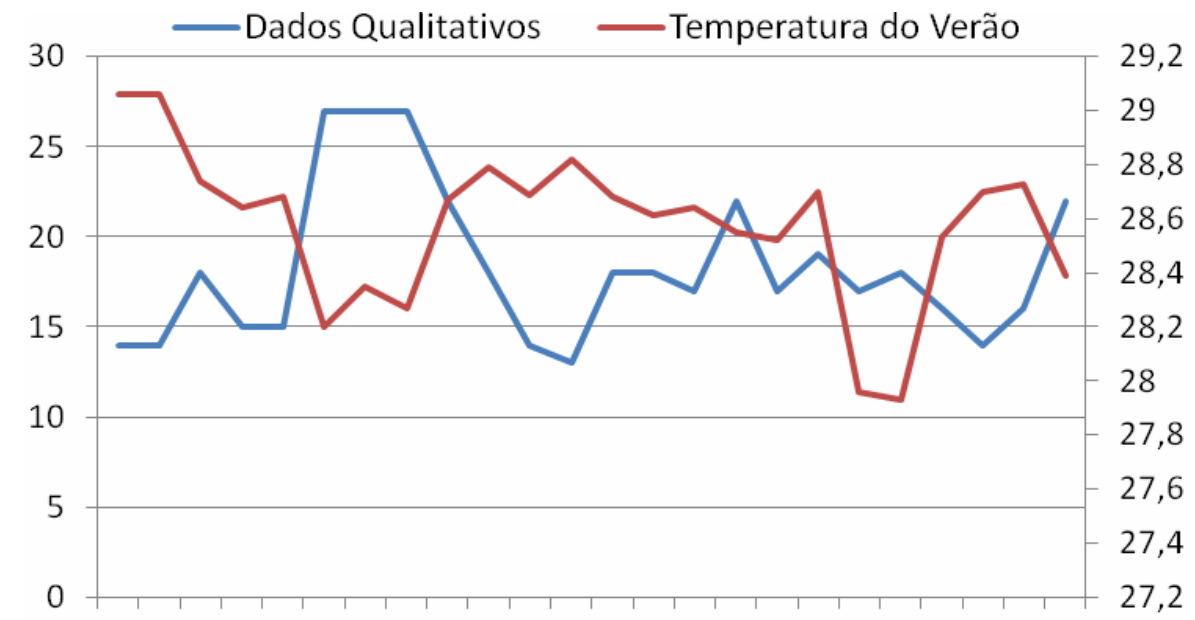

123345567899101112131415161718192021222324

Figura 4 - Resultado entre temperatura do ar e dados qualitativos

Os pontos 6, 7 e 8, ficam nas proximidades de um córrego, e os pontos 19 e 20 ficam próximos ao rio Cuiabá, na figura 4 observa-se que apresentam os picos de menores temperaturas do ar e maiores indices bioclimáticos. Duarte (2000) afirma que reservatórios de água, juntamente com o uso de vegetação e do sombreamento permitem a criação de espaços ao ar livre com um microclima diferenciado, aumentando a umidade do ar, reduzindo ganhos térmicos pela radiação solar e diminuindo a temperatura do ar. Robitu et. al (2006) afirma que as árvores e os reservatórios de água devem ser considerados como meios reais para a melhoria das condições microclimáticas no espaço exterior. O resfriamento evaporativo é indiscutivelmente uma das formas mais eficientes de refrigeração passiva para edifícios e espaços urbanos em regiões quentes (GIVONI, 1991).

Situação essa expressada pela pesquisa realizada através da coleta de dados em que podemos verificar a diferença de temperatura do ar entre os pontos que possuem vegetação e 
água com os que não possuem, como exemplo temos o ponto 1 com temperatura do ar de $29,06^{\circ} \mathrm{C}$ contra $27,9^{\circ} \mathrm{C}$ do ponto 19 (figura 5) uma diferença de $1,19^{\circ} \mathrm{C}$.
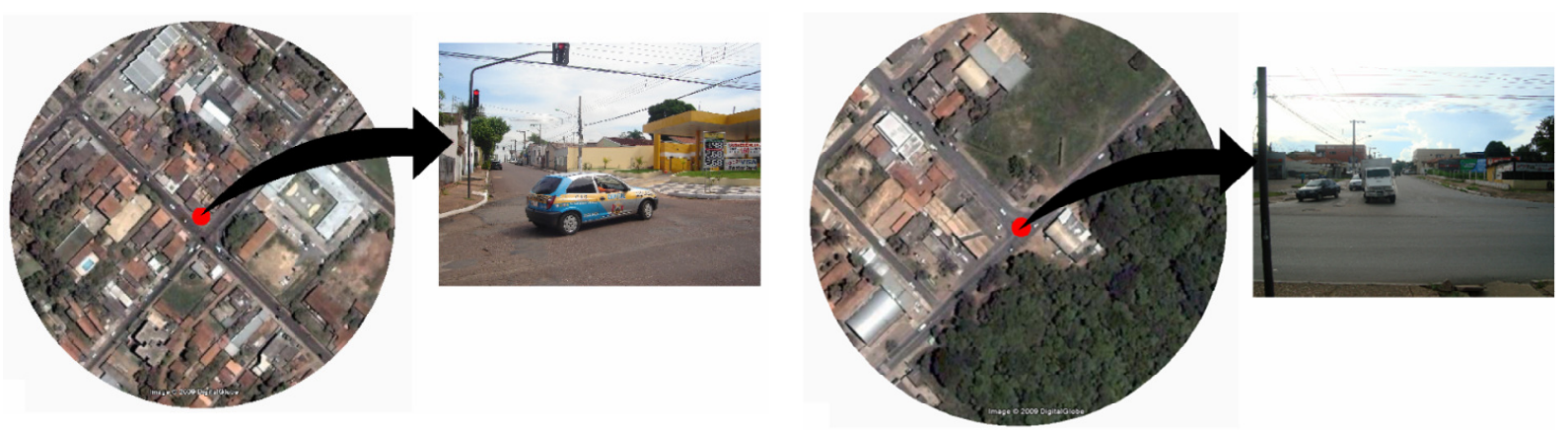

Figura 5 - Pontos de coleta de dados 1 e 19 respectivamente

Na Figura 4 apresenta o comparativo entre a temperatura do ar e os dados bioclimáticos, e pode-se ser notada uma relação inversamente proporcional sendo assim comprovadamente a análise qualitativa do ambiente microclimático é importante, pois já direciona o pesquisador a respeito de qual é o comportamento esperado de cada local. Os Pontos com maiores temperaturas do ar foram onde encontramos os valores mais baixos na classificação bioclimática, ou seja ausência de vegetação e cursos d'água uso e ocupação do solo misto ou comercial, construções sem afastamentos, fatores que criam um ambiente térmico desfavorável ao clima quente de Cuiabá.

\section{CONSIDERAÇÕES FINAIS}

O planejamento urbano é algo fundamental para o bom desenvolvimento citadino, a realidade das cidades brasileiras é bem diferente da teoria, nos deparamos com um crescimento que não leva em consideração vários fatores, dentre eles, os ambientais, pois temos uma expansão pautada em interesses politicos e mercadológicos.

O estudo realizado verifica a importância de uma analise qualitativa dos atributos bioclimáticos urbanos, confirmando a importância das diretrizes de planejamento, tendo em vista, que o conforto ambietal, seja uma preocupação atual com o ocupante do espaço de uso público. A análise de dados qualitativos antes da coleta de dados ambientais se mostra importante, pois a mesma, pode servir de diretriz para uma coleta de dados mais precisa e eficiente.

\section{AGRADECIMENTOS}

A CAPES, ELETROBRÁS e ao Pograma de Pós-Graduação em Física Ambiental/UFMT pela realização da pesquisa. 


\section{REFERÊNCIAS BIBLIOGRÁFICAS}

DUARTE, D. H. S. (2000) Padrões de ocupação do solo e microclimas urbanos na região de clima tropical continental. Tese (Doutorado em Arquitetura). Faculdade de Arquitetura e Urbanismo da Universidade de São Paulo. São Paulo

GIVONI, B. (1991) Impact of planted areas on urban environmental quality: a review. Atmospheric Environment, Oxford, v.25B, n.3, p.289-199

GIVONI, B. (1994) Passive and Low Energy Cooling of Buildings. New York: John Wiley \& Sons

ROMERO, M. A. Arquitetura Bioclimática do Espaço Público. 1.ed. Brasília: Editora Universidade de Brasília, 2001.

ROBITU M., MUSY M., INARD C.,GROLEAU D. (2006) Modeling the influence of vegetation and water pond on urban microclimate. Solar Energy v80

SANTAMOURIS M., GAITANI N., SPANOU A., SALIARI M., GIANNOPOULOU K.,VASILAKOPOULOU K., KARDOMATEAS T. (2012) Using cool paving materials to improve microclimate of urban areas e Design realization and results of the flU. Us project. Building and Environment v53

SHASHUA-BAR L.,TSIROS I. X., HOFFMAN M. E. (2010) A modeling study for evaluating passive cooling scenarios in urban streets with trees. Case study: Athens, Greece. Building and Environment v45

SIQUEIRA E. M.; ALENCASTRO A.; CONTE C. Q.; LACERDA L. B., Cuiabá: de vila a metrópole nascente. Textos vários autores. $2^{\circ}$ Ed. Cuiabá: Editora Entrelinhas, 2007. 